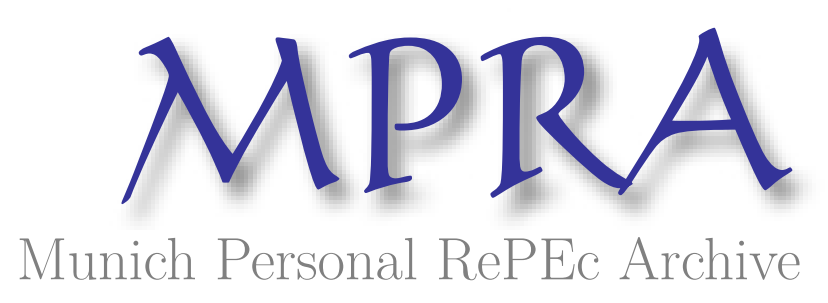

\title{
Dynamic Stock Market Participation of Households
}

Khorunzhina, Natalia

Copenhagen Business School

November 2011

Online at https://mpra.ub.uni-muenchen.de/35310/

MPRA Paper No. 35310, posted 09 Dec 2011 14:21 UTC 


\title{
Dynamic Stock Market Participation of Households *
}

\author{
Natalia Khorunzhina \\ Department of Economics \\ Copenhagen Business School \\ nk.eco@cbs.dk
}

November, 2011

${ }^{*}$ The author is grateful to Jean-Francois Richard, David DeJong, Robert Miller, Randall Walsh, James Feigenbaum, WayneRoy Gayle, and George-Levi Gayle for discussions and insightful comments. The author also thanks participants at the Midwest Econometrics Group meetings (Purdue University, September 2009, and Washington University in St. Louis, October 2010), QSPS 2010 Summer Workshop (Utah State University, May 2010), 2011 North American Summer Meeting of the Econometric Society (Washington University in St. Louis), and Panel Data Conference (Montreal, Canada, July 2011). All errors are mine alone. 


\begin{abstract}
This paper develops and estimates a dynamic model of stock market participation, where consumers' decisions regarding stock market participation are influenced by participation costs. The practical significance of the participation costs is considered as being a channel through which financial education programs can affect consumers' investment decisions. Using household data from the Panel Study of Income Dynamics, I estimate the magnitude of the participation cost, allowing for individual heterogeneity in it. The results show the average stock market participation cost is about 5\% of labor income; however, it varies substantially over consumers' life. The model successfully predicts the level of the observed participation rate and the increasing pattern of stock market participation over the consumers' life cycle.

JEL C33, D12, D91, G11

Keywords: Portfolio Choice, Stock Market Participation, Dynamic Models, Discrete Choice Models, Panel Data.
\end{abstract}




\section{Introduction}

Despite the theoretical prediction that all investors will participate in stock markets if the equity premium is positive, empirical evidence shows a substantial number of consumers do not invest in stock markets either directly or indirectly (via pension account schemes, mutual funds, or similar institutions). ${ }^{1}$ Over the past decade, the so-called limited stock market participation phenomenon has received growing attention in both the theoretical and empirical literature. One of the popular explanations for the phenomenon is the existence of stock market participation costs that arise from the time and effort necessary for obtaining and processing financial knowledge and information, for following the current trends on financial markets, for paying sign-up fees, for filing the necessary paperwork associated with stock holdings, and so on. Stock market participation costs, however, are not observed by researchers, which comprises the major difficulty in quantifying it. Yet using the data to reveal the magnitude of the participation cost and its sources of heterogeneity is important for a number of reasons. First, participation cost is one of the parameters in life-cycle models of portfolio allocation and wealth accumulation; therefore, its various magnitudes can lead to different implications and may result in different economic policy conclusions. Second, economic programs that aim to provide financial education to consumers may lead to reduced participation costs, thereby encouraging stock market participation. However, the effect of such programs is likely to differ for different groups of consumers. This paper develops and estimates a dynamic model of stock market participation, in which participation costs influence consumers' decisions regarding stock market participation. Using household data from the Panel Study of Income Dynamics, I estimate the magnitude of the stock market participation cost, allowing for individual heterogeneity in participation costs, represented by age, education, and participation experience.

Over the past century, average returns on equity have far exceeded the average returns on risk-free assets. In light of impressive equity premium over these years, the unwillingness to invest in stocks is arguably an investment mistake (Campbell, 2006; Calvet, Campbell, and Sodini, 2007). The launching of financial education curricula via a number of economic policy incentives a decade ago acknowledged the importance of the promotion of consumer financial education. ${ }^{2}$ Further, a growing concern in the literature and in economic policy debates reinforced the issue of limited stock market participation (see Guiso and

\footnotetext{
${ }^{1}$ See, for example, Haliassos and Bertaut (1995), Heaton and Lucas (2000), Vissing-Jorgensen (2002), and a collection of papers in "Household Portfolios" by Guiso, Haliassos, and Jappelli, Cambridge, MA: MIT Press.

${ }^{2}$ Examples are the Economic Growth and Tax Relief Reconciliation Act, and Money Smart, a program launched by the Federal Deposit Insurance Corporation.
} 
Japelli, 2005; Campbell, 2006; and Lusardi, van Rooji and Alessie, 2007). Recently, the debates resulted in a number of financial education programs designed to further increase and promote financial literacy among consumers. ${ }^{3}$ Financial education and counseling alleviates the burden on consumers' time and the effort necessary for making financial decisions and reduces the objective cost of stock market participation. In life-cycle models of portfolio allocation and wealth accumulation, participation cost may be viewed as a modeling tool that allows us to investigate whether financial education programs can influence consumers' financial choices and increase participation in financial markets.

Although stock market participation costs are not observed, the literature has collected supporting evidence that participation costs are non-negligible. Theoretical simulations of Haliassos and Michaelides (2003) and Gomes and Michaelides (2003) show that a stock market entry cost or participation cost can rationalize not participating in stock markets. Vissing-Jorgensson (2002), Paiella (2007), and Attanasio and Paiella (2011) look for further evidence in an empirical framework and confirm that small fixed participation costs can explain the observed low participation rate. However, the literature finds little agreement on the size of the participation costs. Haliassos and Michaelides (2003) obtain a wide range for entry costs, from $3 \%$ to $34 \%$ of mean annual income. Alan (2006) finds stock market entry costs equal about $2 \%$ of annual permanent income. The existing empirical estimates of per-period participation costs only provide a lower bound. Attanasio and Paiella (2011) and Paiella (2007) estimate the lower bound of participation costs in units of nondurable consumption are as low as $0.4 \%$ and $0.7 \%$ of consumption per year. ${ }^{4}$ Although these estimates show investor behavior is sensitive even to small changes in consumption, the estimated lower bounds of participation costs provide limited information for further analysis of economic welfare. A sharper estimate of participation costs can be beneficial for evaluation of policy interventions in models of lifetime consumption and portfolio choice. The leading measure of the participation costs in those models is a fixed share of labor income (see Gomes and Michaelides, 2003, and the subsequent studies). In line with this literature, I estimate participation costs as a share of labor income; however, I go one step further by exploring the heterogeneity of participation costs.

The empirical studies cited earlier necessarily adopt a broad definition of the participation costs, which include both pecuniary (financial) and non-pecuniary (behavioral) components, because insufficient data usually hinders separate identification of these components. The notable exception is the work of Andersen

\footnotetext{
${ }^{3}$ The latest incentive is the Dodd-Frank Wall Street Reform and Consumer Protection Act of 2010.

${ }^{4}$ These estimates translate into a $\$ 72$ bound for Attanasio and Paiella (2011) and a $\$ 130$ bound for Paiella (2007). VissingJorgensen (2002) finds per-period fixed costs as low as \$260 can explain the behavior of most nonparticipants.
} 
and Nielsen (2011), whose unique data allow for separation of the effects of financial and behavioral costs. They find limited stock market participation is not likely to be driven by financial constraints but rather by behavioral, cognitive, and psychological barriers. Duflo and Saez (2000) and Hong, Kubik, and Stein (2004) investigate how one's peers affect participation, offering additional evidence in favor of behavioral motives and cognitive abilities as barriers to stock market participation. Grinblatt, Keloharju and Linnainmaa (2009) show a link between IQ and stock market participation. Although the structural model developed in this paper does not directly connect to this strand of the literature due to limitations in the data, the flexible form of participation costs enables me to account for non-financial barriers to stock market participation and evaluate the cohort effects in participation. In doing so, I allow the participation costs to depend on investor's education as a proxy for the ability to collect and process information and on age and past participation as proxies for the accumulation of information and experience.

My analysis departs from the life-cycle consumption and portfolio choice model, as in Gomes and Michaelides (2003), where households optimize lifetime utility subject to the wealth-accumulation budget constraint. The key component of the analysis of participation cost is the intertemporal utility cost and benefit that arises with different participation strategies. Stock market participation costs have a direct effect on savings. They are also connected to the share of wealth households choose to invest in stocks. On the one hand, the participation cost reduces savings today - a risk a household takes in the hopes of receiving a greater expected return on its portfolio and a corresponding increase in wealth in the next period. On the other hand, households may choose not to invest in stocks today, but instead keep all savings in risk-free assets. In the next period, however, the household receives a risk-free return on wealth, which also includes the not-foregone participation cost. The estimation of the participation costs relies on comparison of the value functions associated with the two participation strategies.

The model falls into a dynamic discrete choice estimation framework. The estimation technique I implement is the modified version of the Conditional Choice Probability (CCP) estimator, originally proposed by Hotz and Miller (1993) for estimation of dynamic discrete choice models. To my knowledge, the current study is the first to use a CCP estimator to estimate households' investment choices. ${ }^{5}$

The estimation results provide evidence that the participation cost, measured as a share of income, can be substantial. It is, on average, greater than the lower-bound estimates of Paiella (2007) and Attanasio and Paiella (2011). The average stock market participation cost is estimated to be about $5 \%$ of labor income;

\footnotetext{
${ }^{5}$ The CCP techniques of Hotz and Miller (1993), Altug and Miller (1998), and Arcidiacono and Miller (2011) are mostly known for estimation of structural models with discrete and continuous choices in labor economics and industrial organization.
} 
however, it varies over the consumer's life. The results show the participation costs are less for more educated investors. As expected, participation costs decrease with stock market participation experience and as consumers become older. When age enters the participation cost in a quadratic form, the participation cost is increasing and concave in age, with the turning point at age 35-40. The estimated model also implies the stock market participation costs are larger for first-time investors. Therefore, the results on stock market participation costs not only support the previous findings in empirical literature, but also are in accordance with the fixed entry costs used in theoretical literature. The striking difference of the estimated structural model with similar models in theoretical studies lies, however, in successful prediction of the low stock market participation rate observed in the data.

The rest of the paper is organized as follows. Section 2 describes data sample construction, followed by reduced-form analysis of the participation rate and share of wealth invested in stocks, and concluding with a discussion about the participation costs and recent developments in economic and financial policies aimed at alleviating them. Section 3 describes the model, preferences, and optimality conditions over portfolio choice. Section 4 discusses the empirical methodology implemented in the estimation of the parameters of interest, and outlines stages of estimation. Section 5 presents the empirical findings of the model. Section 6 reports a solution for the dynamic programming model and illustrates how the model fits the data. Section 7 concludes.

\section{The Microeconomic Picture: Data and Discussion}

This section discusses the data and the choice of relevant variables. I conduct a reduced-form analysis to determine the covariates that are particularly powerful in explaining the decision to invest in stock markets. The results of the reduced-form analysis also help to motivate the choice of covariates that can contribute to the characterization of the stock market participation cost. Then I describe construction of three data subsets used in three estimation stages.

\subsection{Data}

Data on household liquid wealth, income, and demographic characteristics are taken from the Panel Study of Income Dynamics (PSID). Starting in 1999, the wealth supplement of the PSID is available every two years. In my analysis, I use observations for five time periods, from 1999 through 2007.

Household stock market participation is a result of a complicated decision making that involves taking 
into consideration various background risks and other investment opportunities. Risky labor income may cause a crowding out of stock market investments. Heaton and Lucas (2000) argue private business assets substitute for public equity. Homeownership and changes in housing may result in shifts of household portfolio away from direct stock holdings. Finally, deep changes in family composition affect household financial portfolio as well. In the current study, however, I try to exclude the potential influence of these factors, and consider households that satisfy the following conditions: (i) do not invest in business and/or farm; (ii) do not experience changes in housing; and (iii) have the same head of household for the whole observation period. Table 1 shows summary statistics for the data I use in my analysis.

\section{Wealth and Income}

The value of households' stock holdings is observed in the PSID as "non-IRA stock holdings."6 Total liquid wealth is computed as a sum of non-IRA stock holdings, money in checking or savings accounts, money market funds, certificates of deposit, government savings bonds, Treasury bills, other bond holdings, and money in other savings or assets, such as bond funds. The value of liquid wealth that is not invested in stocks is considered a risk-free asset. Total household income consists of labor income, financial income (interest, dividends, income from trust fund), and other money inflow (child support, help from relatives, rent, worker's compensation) of the head of the household and the spouse. Top-coded observations on wealth and income are excluded from the sample. I also remove extreme outliers by excluding observations for wealth and income above the 99th percentile and below the 1st percentile. Data on income and wealth are deflated using the CPI for the end of the year before the interview was conducted. The CPI deflator is taken from the consumer price index releases of the Bureau of Labor Statistics.

Table 1 shows the dramatic difference in both income and wealth between participants and nonparticipants. On average, nonparticipants have a lower income. The accumulated wealth of nonparticipants is substantially lower as well. However, larger standard deviations accompany the greater average income and wealth of stock market participants.

\section{Demographics}

Demographic characteristics include age, education, and occupation of the head of the household, as well as marital status and family size. Individual consumption and savings behavior differs depending on the consumer's stage of life: in prime working age or at retirement. This study mostly considers prime-age consumers and excludes households whose head is either younger than 22 or older than 65 over the period

\footnotetext{
${ }^{6}$ The PSID separately provides information on the total amount held in individual retirement accounts and an approximate split of the amount in an IRA between interest- and dividend-earning assets. The exact value of an IRA in stock holdings is not available.
} 
Table 1: Summary Statistics

\begin{tabular}{|c|c|c|c|c|c|}
\hline Year & 1999 & 2001 & 2003 & 2005 & 2007 \\
\hline \multicolumn{5}{|l|}{ Income and Wealth $^{a}$} & 1,524 \\
\hline Income & $39,420.6$ & $39,532.9$ & $38,748.0$ & $40,040.0$ & $40,252.8$ \\
\hline Nonparticipants & $34,716.9$ & $35,363.8$ & $35,698.1$ & $36,913.2$ & $36,965.0$ \\
\hline & $(19,885.0)$ & $(21,087.4)$ & $(21,198.6)$ & $(22,709.3)$ & $(22,290.0)$ \\
\hline Participants & $50,740.6$ & $50,243.1$ & $46,938.1$ & $49,565.4$ & $51,530.6$ \\
\hline & $(29,623.8)$ & $(27,695.0)$ & $(29,134.3)$ & $(30,019.2)$ & $(29,623.2)$ \\
\hline Wealth & $21,525.4$ & $21,974.9$ & $23,793.2$ & $22,864.0$ & $21,859.5$ \\
\hline Nonparticipants & $10,407.1$ & $10,725.3$ & $11,440.3$ & $10,338.6$ & $10,532.2$ \\
\hline & $(23,649.3)$ & $(25,346.4)$ & $(27,277.2)$ & $(22,870.9)$ & $(25,020.8)$ \\
\hline Participants & $48,283.5$ & $50,874.2$ & $56,965.1$ & $61,022.1$ & $60,714.7$ \\
\hline & $(58,981.7)$ & $(64,580.2)$ & $(71,231.2)$ & $(74,778.4)$ & $(71,578.9)$ \\
\hline Stock holders & 0.29 & 0.28 & 0.27 & 0.25 & 0.22 \\
\hline Share of wealth in stock & 0.61 & 0.58 & 0.53 & 0.55 & 0.57 \\
\hline Stock holdings of participants & $32,883.1$ & $32,979.9$ & $32,451.9$ & $37,838.5$ & $37,270.7$ \\
\hline \multicolumn{6}{|l|}{ Demographic data } \\
\hline Age & 43.3 & 44.3 & 45.1 & 46.1 & 46.0 \\
\hline Nonparticipants & 42.6 & 43.7 & 44.6 & 45.4 & 45.4 \\
\hline Participants & 44.8 & 46.0 & 46.5 & 48.3 & 48.0 \\
\hline & 3.03 & 3.00 & 2.93 & 2.94 & 2.89 \\
\hline \multirow{2}{*}{ Family size } & 3.10 & 3.02 & 2.97 & 2.99 & 2.92 \\
\hline & 2.87 & 2.94 & 2.82 & 2.80 & 2.78 \\
\hline & 13.7 & 13.6 & 13.6 & 13.7 & 13.7 \\
\hline \multirow{2}{*}{ Education } & 13.3 & 13.3 & 13.3 & 13.4 & 13.4 \\
\hline & 14.6 & 14.6 & 14.5 & 14.6 & 14.7 \\
\hline \multirow[t]{3}{*}{ Marital status } & 0.70 & 0.70 & 0.70 & 0.71 & 0.71 \\
\hline & 0.69 & 0.67 & 0.67 & 0.68 & 0.68 \\
\hline & 0.74 & 0.78 & 0.76 & 0.79 & 0.79 \\
\hline \multirow[t]{3}{*}{ Occupation $^{b}$} & n.a. & n.a. & 0.16 & 0.17 & 0.16 \\
\hline & & & 0.13 & 0.15 & 0.14 \\
\hline & & & 0.23 & 0.23 & 0.26 \\
\hline
\end{tabular}

${ }^{a}$ Standard deviation is reported in parenthesis.

${ }^{b}$ Equals to 1 if related to management, business operation, or financial specialist; 0 otherwise. 
of the estimation. I also exclude households whose marital status changed over the sample period.

Table 1 shows differences in demographic characteristics of participants and nonparticipants. On average, participants are two to three years older and more educated. Their occupation is typically more related to management, business operations, or finance. More married individuals are among stock market participants compared to nonparticipants. The difference in family composition is not substantial.

\section{Rates of Return}

Uncertainty about returns on risky assets plays an important role in dynamic decisions about participation and portfolio composition. Additional information is necessary for assessing the realizations of the household-specific rates of return on stock holdings and risk-free assets.

The PSID provides data not only on the value of stock holdings, but also, the amount invested in or taken out of stocks between periods $t-1$ and $t$. Then the household-specific rate of return on stock holdings $R_{i t}^{s}$ can be computed using the household data on total value of stock holdings and sales (purchases) of stocks from the constraint $S_{i t}=s_{i t}+R_{i t}^{s} S_{i t-1}$, where $S_{i t}$ is the total value of stock held by household $i$, and $s_{i t}$ is the value of purchases or sales of stock between periods $t-1$ and $t$ for household $i$. Unfortunately, data in the wealth supplement of the PSID are known to suffer from systematic underreporting of trades. The "forgotten" trades affect the computed idiosyncratic rates of return and often make them either unrealistically large or small. This caveat makes using the computed $R_{i t}^{s}$ as a rate of return on households' stock holdings problematic. Nevertheless, the information on the computed $R_{i t}^{s}$ can be used to construct an indicator on whether a household received a high, moderate, or low return on stock holdings in the current period, conditional on participation in the previous period.

I construct the indicator for high, moderate, or low rate of return by matching the household specific rate of return on stock holdings $R_{i t}^{s}$ with the distribution of the market index rate for the period. I use the SP500 index. The indicator for low (high) return is equal to one if the household-specific rate of return on stock holdings $R_{i t}^{s}$ is one or more standard deviations below (above) the market index. Standard deviation of the index for 1999-2007 period is about 0.20, with a bi-annual standard deviation at a larger value of about

0.30 . I construct the real risk-free rate $R_{t}^{f}$ based on seasonally adjusted deflated average six-month Treasury bill.

Table 2 reports summary statistics for the risk-free rate and rates of return on stock holdings. Years of turbulence in the financial markets characterize the time period I consider. This characterization is reflected in the rates of return on market indices, which vary substantially over the reported period. In spite of the data 
Table 2: Rates of Return

\begin{tabular}{lccccccccc}
\hline \hline & 1999 & 2000 & 2001 & 2002 & 2003 & 2004 & 2005 & 2006 & 2007 \\
& & & & & & & & & \\
\hline & & & & & & & & & \\
$R^{f}$ & 0.020 & 0.026 & 0.020 & -0.008 & -0.008 & -0.019 & 0.000 & 0.024 & 0.000 \\
Nasdaq & 0.581 & -0.246 & -0.242 & -0.307 & 0.547 & -0.021 & 0.082 & 0.056 & -0.063 \\
SP500 & 0.070 & -0.044 & -0.165 & -0.249 & 0.305 & 0.016 & 0.043 & 0.105 & -0.079 \\
$R^{s *}$ & -0.029 & -0.114 & 0.067 & 0.024 & \\
$\mathcal{F}_{t}^{L}$ & 0.428 & 0.427 & 0.344 & 0.318 & \\
$\mathcal{F}_{t}^{M}$ & 0.277 & 0.283 & 0.327 & 0.371 & \\
$\mathcal{F}_{t}^{H}$ & 0.295 & 0.290 & 0.329 & 0.311 & \\
& & & & & & & & \\
\hline \hline
\end{tabular}

${ }^{*} R^{S}$ is the median of ex-post annual rate between two consecutive time periods, calculated from the wealth supplement of the PSID and reported for stock market participants only. $\mathcal{F}_{t}^{k}$ for $k=\{L, M, H\}$ is the probability of the individual return of stock $R^{S}$ being one standard deviation lower, in between, or greater than the average return on the SP500 for the observed time period, calculated from the data. Returns are inflation adjusted.

deficiencies in the reported stock holdings, the median for the computed household-specific rate of return $R^{s}$ admits reasonable values and follows the trend of market indices. ${ }^{7}$ One can see the presence of two "regimes" in the empirical distribution of the computed rates of return. From 1999 to 2002, smaller values of returns were prevalent. The turbulence of the financial markets most affected these years. From 2003 to 2007, small, medium, and large returns showed similar weights. This evidence is consistent with the period of stability in financial markets during this time.

\subsection{Regression Analysis}

Table 1 shows the observed characteristics of households in the sample differ significantly between participants and nonparticipants. The difference between participants and nonparticipants is especially striking along the dimensions of liquid wealth, income, age, and education. In this section, I analyze the probability of investing in stocks and the share of wealth invested in stocks. I estimate Heckman's sample selection model (Heckman, 1979) to determine the covariates that are particularly powerful in explaining the decision to invest in stock markets and the portfolio allocation of stock market participants.

Table 3 reports the estimation of the participation equation and the share of wealth in stocks. The average participation rate in the sample is $24 \%$. A history of past participation in stock markets has a dramatic

\footnotetext{
${ }^{7}$ The average household-specific return is not so meaningful, because of the substantial number of computed rates that are either very large or very small, depending on the time period.
} 
Table 3: Regressions for stock market participation and share of wealth invested in stocks, Heckman twostep estimator.

\begin{tabular}{|c|c|c|}
\hline Variable & Participation & Share \\
\hline History of participation in the past & $\begin{array}{l}1.337^{*} \\
(0.050)\end{array}$ & \\
\hline Income & $\begin{array}{c}0.069^{*} \\
(0.026)\end{array}$ & $\begin{array}{l}0.010 \\
(0.008)\end{array}$ \\
\hline Income $^{2} / 1000$ & $\begin{array}{c}-2.841 \\
(1.991)\end{array}$ & $\begin{array}{c}-0.235 \\
(0.570)\end{array}$ \\
\hline Wealth $_{t-1}$ & $\begin{array}{c}0.068^{*} \\
(0.012)\end{array}$ & $\begin{array}{l}0.004 \\
(0.004)\end{array}$ \\
\hline Wealth $_{t-1}^{2} / 1000$ & $\begin{array}{c}-1.244^{* *} \\
(0.486)\end{array}$ & $\begin{array}{c}-0.007 \\
(0.134)\end{array}$ \\
\hline Age & $\begin{array}{c}0.032^{* * *} \\
(0.019)\end{array}$ & $\begin{array}{l}0.005 \\
(0.008)\end{array}$ \\
\hline $\mathrm{Age}^{2} / 1000$ & $\begin{array}{c}-0.215 \\
(0.154)\end{array}$ & $\begin{array}{c}-0.045 \\
(0.061)\end{array}$ \\
\hline Education & $\begin{array}{c}0.078^{*} \\
(0.011)\end{array}$ & $\begin{array}{l}0.001 \\
(0.004)\end{array}$ \\
\hline Male & $\begin{array}{l}0.040 \\
(0.084)\end{array}$ & $\begin{array}{c}-0.008 \\
(0.032)\end{array}$ \\
\hline White & $\begin{array}{c}0.444^{*} \\
(0.065)\end{array}$ & $\begin{array}{c}-0.007 \\
(0.031)\end{array}$ \\
\hline Married & $\begin{array}{c}-0.019 \\
(0.039)\end{array}$ & $\begin{array}{c}-0.042 \\
(0.031)\end{array}$ \\
\hline Family size & $\begin{array}{c}-0.009 \\
(0.026)\end{array}$ & $\begin{array}{c}-0.013 \\
(0.015)\end{array}$ \\
\hline Number of children & $\begin{array}{c}-0.006 \\
(0.047)\end{array}$ & $\begin{array}{l}0.029 \\
(0.018)\end{array}$ \\
\hline Constant & $\begin{array}{c}-3.977^{*} \\
(0.622)\end{array}$ & $\begin{array}{c}0.547^{* * *} \\
(0.294)\end{array}$ \\
\hline Mills & & $\begin{array}{c}-0.047^{* *} \\
(0.021)\end{array}$ \\
\hline
\end{tabular}

$* * *$, and $* * *$ denote the $1 \%, 5 \%$, and $10 \%$ significance level, respectively. Wald $\chi_{(50)}^{2}=355.8$. Regression uses 5,107 observations recorded between 2001 and 2007, which includes 1,415 uncensored observations. Age cohort dummies, time dummies, and region dummies are included in all regressions. Age cohort dummies are constructed in 5-year intervals to break the linear dependence between age, time dummies, and age cohort dummies (see Gomes and Michaelides, 2005; Campbell, 2006). Standard errors are in parentheses. 
effect on the participation rate as it increases the probability of current participation by $44 \%$. Participation rate is increasing and concave in past wealth. It also increases with income. After controlling for age cohorts and time dummies, the effect of age on the decision to participate is still positive. Better educated households are more likely to participate in stock markets. The probability of participation in stock markets is substantially greater for households with a head whose race is white. All of the demographic covariates in the outcome equation for the share of wealth invested in stocks are statistically insignificant. Only the constant is estimated to be marginally significant at the 0.54 level.

The evidence that age, education and past participation experience have a significant positive effect on stock market participation may support the existence of an information cost to participation. Education generally proxies for the ability to collect and process information. Age and past participation can proxy for the accumulation of information and experience. The regression analysis suggests participation cost may depend on these demographic characteristics and is likely to decline in education and age and be smaller for households that invested previously in stock markets.

Participation in stock markets requires not only financial knowledge, but also time effort. The opportunity cost of participation can be measured as a fixed share of income. Indeed, the leading measure of the participation cost in the literature is a fixed amount of labor income (see Gomes and Michaelides (2003) and the subsequent studies). In line with this literature, I construct participation cost as a share of labor income.

\subsection{Data Sets Used in Estimation}

For the analysis that follows, I take into account the data restrictions discussed above and construct three data samples. The samples include a data subset used in estimation of the preference parameters and the parameters of the participation cost, a data subset with an extended time frame for estimation of the earnings' equation, and a data subset with an extended number of individuals to estimate the conditional choice probabilities.

The first stage of analysis involves the estimation of the individual effects. I use the earnings equation to estimate individual unobserved fixed effects. To reduce the bias in fixed effects, one needs a data sample with a larger time dimension. Unlike the wealth data, labor income is reported in the PSID in all time periods well beyond the period for which the wealth supplement is available. To estimate the earnings' equation, I take the extended data set from 1981 through 2007. Because the main model only uses data on odd years, for consistency, I use data on odd years only. Using the age and income restrictions described above, I 
construct an extended data set of 7,744 households that contains data on each household's labor income, age, education, and family size.

The second stage of the analysis estimates conditional choice probabilities that also require a large number of observations, especially along the cross-sectional dimension of the panel. This data set is constructed using wealth variables, among others, so it has time dimension from 2001 (accounting for one lag in wealth) through 2007. To ensure a larger number of observations, I drop the age and marital status restrictions discussed above. Namely, I use households of all ages and disregard the changes in marital status while still controlling for marital status, and age. The conditioning set for estimation of conditional choice probabilities includes past wealth, past share in wealth invested in stocks, return on household portfolio, income, age, education, occupation, family size, and marital status as well as estimated individual effects and time dummies from the earnings' equation. A total of 10,708 observations are available over four time periods.

Finally, the third stage of the analysis estimates the preference parameters and the parameters of the participation cost. This data sample is constructed as an unbalanced panel of 299 households observed over three periods: 2001, 2003, and 2005. Two other time periods (1999 and 2007) are lost while taking one lag and one lead. I observe these households participating in stock markets in the current period. Regarding the treatment of the self-selection issue, note the following: first, although the utility parameters are estimated with stock market participants, the construction of the estimator allows me to fully use the information on nonparticipants in the estimation of the individual effects and the conditional choice probabilities in the previous stages of estimation; therefore, I incorporate this information into the estimation of the final stage through the estimates of unobserved effects and CCPs. Second, I construct the third-stage estimator from an identity equation that holds equally for participants and nonparticipants.

The set of model covariates includes past and current wealth, the past and current share of wealth invested in stocks, current and future income, current demographic characteristics, as well as estimates of the conditional choice probabilities, and transition probabilities. I compute transition probabilities $\mathcal{F}_{t}^{k}$ for $k=\{L, M, H\}$ from the data as reported in Table 2. The instrument set for orthogonality conditions includes variables from the state vector: the past share of wealth invested in stock, past portfolio allocation, return on household portfolio, income, and family characteristics.

\section{Model}

This section develops the theoretical framework to investigate household portfolio choices. 
$N$ households are indexed by $i=1, \ldots, N$, each with a lifespan of $T$ periods. In each period, household $i$ observes its accumulated wealth and a current rate of return on the portfolio composed of riskless and (possibly) risky assets. After observing income, the household observes the amount of cash on hand to be allocated between a single composite consumption good and savings. ${ }^{8}$ The household also decides how to reallocate savings between risky and riskless asset. In each period, the household decides to either invest in stocks, denoted by $d_{i t}=1$, or to not invest and instead keep all savings in the riskless assets, in which case $d_{i t}=0$. If the household decides to invest in stocks, it also chooses the share of wealth allocated to stock holdings, represented by $\alpha_{i t}$.

Let $z_{i t}$ be the state vector of household $i$ in period $t$ that is composed of observed and unobserved characteristics. Let $d_{j i t}$ for $j=0,1$ be the indicator for participation choices: $d_{1 i t}=1$ if the household $i$ invests in stocks in period $t$, and $d_{0 i t}=1$ if the household $i$ does not participate in stock markets, so that $d_{0 i t}+d_{1 i t}=1$. In every period, household $i$ receives a utility payoff $u_{j}\left(z_{i t}\right)+\varepsilon_{j i t}$, where $u_{j}\left(z_{i t}\right)$ depends on consumption and stock market participation choices and $\varepsilon_{j i t}$ is a choice-specific utility shock, independent over $i$ and $t$, which is revealed to the household at the beginning of period $t$. The household's problem can be formulated as follows:

$$
\begin{aligned}
& \max _{d_{i t}} \mathbb{E}_{i t} \sum_{\tau=t}^{T} \sum_{j=0}^{1} \beta^{\tau-t} d_{j i \tau}\left[u_{j}\left(z_{i \tau}\right)+\varepsilon_{j i \tau}\right] \\
& \text { subject to: } \quad w_{i t}=R_{i t}^{p} w_{i t-1}+y_{i t}-c_{i t}-d_{i t} \rho_{i t},
\end{aligned}
$$

where the expectation is taken conditional on the state vector $z_{i t}, \beta \in(0,1)$ is the subjective time-discount factor, $y$ is the household's income, $c$ is consumption, and $w$ is total liquid wealth (stocks, bonds, cash accounts, and similar liquid assets). $R^{s}$ is the real return on the risky assets held by the household and $R^{f}$ is the return on the riskless assets, the combination of which gives the return on the portfolio $R_{t}^{p}=$ $\alpha_{t-1} R_{t}^{s}+\left(1-\alpha_{t-1}\right) R_{t}^{f}$. If a household decides to invest in stocks, it gives up a per-period participation cost $\rho$. Problem (3.1) is maximized by a Markov decision rule.

Let $V_{t}\left(z_{i t}\right)$ be the (ex-ante) value function in period $t$, that corresponds to the optimization problem (3.1). The value function $V_{j t}\left(z_{i t}\right)$ conditional on the choice $j$ can be written as $V_{j t}\left(z_{i t}\right)=v_{j t}\left(z_{i t}\right)+\varepsilon_{j i t}$, where $v_{j}\left(z_{i t}\right)$ is the conditional value function explained by $z_{i t}$, and $\varepsilon_{j i t}$ is a stochastic component, as defined above, that an econometrician does not observe. The optimal participation decision rule involves comparing value

\footnotetext{
${ }^{8}$ I do not model household labor supply decisions, and I assume household supplies labor in each period.
} 
functions associated with each participation choice. The optimal decision $d_{i t}^{o}$ of household $i$ in period $t$ can be expressed as follows:

$$
d_{i t}^{o} \equiv \begin{cases}1 & \text { if } \quad v_{1 t}\left(z_{i t}\right)+\varepsilon_{1 i t} \geqq v_{0 t}\left(z_{i t}\right)+\varepsilon_{0 i t} \\ 0 & \text { otherwise }\end{cases}
$$

From equation (3.2), the conditional probability of participation in stock markets can be represented as $p_{1 i t}=p_{1}\left(z_{i t}\right)=\mathbb{E}\left[d_{i t}^{o}=1 \mid z_{i t}\right]$ and $p_{0 i t}=p_{0}\left(z_{i t}\right)=\mathbb{E}\left[d_{i t}^{o}=0 \mid z_{i t}\right]$. Hotz and Miller (1993) prove the existence of a mapping, by which the difference in conditional value functions $v_{1 t}\left(z_{i t}\right)-v_{0 t}\left(z_{i t}\right)$ can be represented as a function of conditional probabilities. Under the assumption that $\varepsilon_{j i t}$ are identically and independently distributed over $(i, t)$ as Type 1 extreme value random variables, the optimality condition (3.2) can be transformed into the following:

$$
\ln \frac{p_{1 i t}}{p_{0 i t}}=v_{1 t}\left(z_{i t}\right)-v_{0 t}\left(z_{i t}\right)
$$

The left-hand side of (3.3) can be estimated directly with the data. The right-hand side can be expressed as a function of current and future utility payoffs. The details on the derivation of the right-hand side of (3.3) follow.

Let $\mathcal{A}_{i t}^{1}$ denote the set of all possible realizations of the state vector for household $i$ at period $t+1$ given the realization of the state vector $z_{i t}$ in period $t$. If the household takes action $j$ at time $t$, the state vector $z_{i t}$ transitions into $z_{i t+1}$ with the probability denoted as $F_{j}\left(z_{i t+1} \mid z_{i t}\right)$. I use the results established in Hotz and Miller (1993) and Arcidiacono and Miller (2011) to derive the conditional value function $v_{j t}\left(z_{i t}\right)$ as follows:

$$
\begin{aligned}
v_{j t}\left(z_{i t}\right) & =u_{j}\left(z_{i t}\right)+\beta \sum_{z_{i t+1} \in \mathcal{A}_{i t}^{1}} V_{t+1}\left(z_{i t+1}\right) F_{j}\left(z_{i t+1} \mid z_{i t}\right) \\
& =u_{j}\left(z_{i t}\right)+\beta \sum_{z_{i t+1} \in \mathcal{A}_{i t}^{1}}\left[v_{0 t}\left(z_{i t+1}\right)+\varphi\left(p_{0}\left(z_{i t+1}\right)\right] F_{j}\left(z_{i t+1} \mid z_{i t}\right)\right. \\
& =u_{j}\left(z_{i t}\right)+\beta \sum_{z_{i t+1} \in \mathcal{A}_{i t}^{1}}\left[u_{0}\left(z_{i t+1}\right)+\xi-\ln \left(p_{0}\left(z_{i t+1}\right)\right)+\beta V_{t+2}\left(z_{i t+2}\right)\right] F_{j}\left(z_{i t+1} \mid z_{i t}\right)
\end{aligned}
$$

where the first equality establishes the conditional value function is composed of the utility payoff of action $j$ and the expected future value conditional on following the optimal decision rule from period $t+1$ on. The second line is written using forward substitution of the conditional value function. It also uses another result of Hotz and Miller (1993) that if $\varepsilon_{j i t}$ are identically and independently distributed over $(i, t)$ as Type 1 extreme value random variables, then the value function can be expressed as a conditional value function plus a function $\varphi$. The function $\varphi$ uses conditional choice probabilities as an argument. In particular, 
$\varphi(p)=\xi-\ln (p)$, where $\xi \approx 0.576$ is Euler's constant. The third line obtains a recursive representation of the conditional value function that is composed of the current and future utility payoffs, functions of conditional choice probabilities, transition probabilities, and the more distant future value function $V_{t+2}$. The important result from this representation is that in many cases under selected participation strategies the conditional value function exhibits finite dependence, such that only a small number of future time periods matter beyond the current period. Because of the finite time dependence property, the current decisions affect only a limited number of future time periods (see Arcidiacono and Miller, 2011, for more details on finite time dependence). More distant value functions become inconsequential for estimation purposes. The model I present can satisfy the one-period finite dependence property under the choice of participation strategy that lead to identical distribution of the state vector $z_{i t+2}$ at time $t+2$. Then the value functions $V_{t+2}$ for two strategies will cancel out while taking differences in equation (3.3), thus inducing finite dependence.

I limit the analysis to only a small number of participation strategies that proves sufficient for estimation of the parameters of interest. Let $x_{i t}$ be an $L$-dimensional vector of exogenous covariates for household $i$ at time $t$. Income is treated as exogenous as well as forecastable and is a part of the vector of exogenous covariates. Define $\tilde{w}_{i t-1}=R_{i t}^{p} w_{i t-1}$ as the period $t$ value of household $i$ 's accumulated wealth. Then the observed state vector for household $i$ at time $t$ is given by the $(L+2)$-dimensional vector $\left(\alpha_{i t-1}, \tilde{w}_{i t-1}, x_{i t}^{\prime}\right)$. The information set $z_{i t}$ is composed of the observed state variables, and the (unobserved) individual heterogeneity statistic $v_{i}$ and aggregate shock $\omega_{t}$, so that $z_{i t}=\left(\alpha_{i t-1}, \tilde{w}_{i t-1}, x_{i t}^{\prime}, v_{i}, \omega_{t}\right)^{\prime}$. Then I define a set of histories as $(2 \times 3+L)$-dimensional vectors $a_{1 k i t}$ and $a_{0 i t}$ with the elements $\left(\alpha_{i t-1}, \alpha_{i t}, \alpha_{i t+1}, \tilde{w}_{i t-1}, \tilde{w}_{i t}, \tilde{w}_{i t+1}, x_{i t}^{\prime}\right)$ as:

$$
\begin{aligned}
& a_{0 i t}=\left(\alpha_{i t-1}, 0,0, \tilde{w}_{i t-1}, \tilde{w}_{i t}, \tilde{w}_{i t+1}, x_{i t}^{\prime}\right), \\
& a_{1 k i t}=\left(\alpha_{i t-1}, \alpha_{i t}^{*}, \quad 0, \tilde{w}_{i t-1}, \tilde{w}_{i t}^{k}, \tilde{w}_{i t+1}, x_{i t}^{\prime}\right)
\end{aligned}
$$

where $\alpha_{i t}^{*}$ is the optimal fraction of wealth a household chooses to invest in stocks, conditional on participating in stock markets in period $t$. Under strategy (3.4), the household chooses not to participate in the stock markets at date $t$ (so that the corresponding state vector becomes $z_{0 i t+1}=\left(0, \tilde{w}_{i t}, x_{i t+1}^{\prime}, v_{i}, \omega_{t+1}\right)$ ), and then does not participate in period $t+1$. Under strategy (3.5), the household chooses to participate in the stock markets at date $t$ (with the corresponding state vector $\left.z_{k i t+1}=\left(\alpha_{i t}, \tilde{w}_{i t}^{k}, x_{i t+1}^{\prime}, v_{i}, \omega_{t+1}\right)\right)$, but does not participate in period $t+1$. If the choice of wealth held in riskless assets in period $t+1$ is the same under both strategies, then the state vectors for both strategies in period $t+2$, given by $z_{i t+2}=\left(0, \tilde{w}_{i t+1}, x_{i t+2}^{\prime}, v_{i}, \omega_{t+2}\right)$, do not differ neither 
in wealth nor in portfolio allocation. The terms in the conditional value function become inconsequential beyond time period $t+1$ from the point of view of optimization.

Once a household decides to invest in risky assets, household wealth at time $t+1$ depends on the realization of the rates of return on stock holding that is unknown to a household when it makes participation choices at time $t$. To integrate over the uncertain returns on risky portfolio allocations, I discretize all possible realizations of the returns on stock holdings to allow for up to $K=3$ possible states conditional on investing, generally described as high, moderate, and low realizations $(H, M, L)$. Transition probabilities associated with the uncertainty on returns on stock holdings are degenerate if the household chooses not to invest in stock markets at time $t$. If the household participates in stock markets in the current period, the probability that the household's liquid wealth moves to one of the possible $K$ states will depend on the realization of the return on the household's portfolio moving over those $K$ states. Transition probabilities are set to be independent of individual investor characteristics, so that $F\left(z_{k i t+1} \mid z_{i t}\right)=\mathcal{F}_{t+1}^{k}$.

After taking the difference in conditional value functions associated with strategies (3.4) and (3.5), the equation (3.3) can be represented as follows:

$$
\ln \frac{p_{1 i t}}{p_{0 i t}}=u_{1}\left(z_{i t}\right)-u_{0}\left(z_{i t}\right)+\beta\left[\sum_{k=1}^{K}\left(u_{0}\left(z_{k i t+1}\right)-u_{0}\left(z_{0 i t+1}\right)\right)-\ln \left(p_{0 k i t+1}\right)+\ln \left(p_{00 i t+1}\right)\right] \mathcal{F}_{t+1}^{k}
$$

where $p_{0 k i t+1}=p_{0}\left(z_{k i t+1}\right)$ is the probability of not participating in stock markets in period $t+1$ conditional on participation in the previous time period and receiving one of the possible $K$ realizations of return on the investment in stocks, and $p_{00 i t+1}=p_{0}\left(z_{0 i t+1}\right)$ is the probability of not participating in the stock markets in period $t+1$ conditional on non-participation in period $t$.

\section{Estimation}

Estimation of equation (3.6) follows a three-step strategy. Step one and two estimate nuisance parameters that include estimates of fixed effects (estimates of unobserved individual heterogeneity), estimates of aggregate shocks, and estimates of conditional choice probabilities. Estimating these parameters is necessary before estimating the parameters of the utility and the participation cost. In particular, fixed effects and aggregate shocks are included in the conditioning set of the value function and conditional choice probabilities. The estimates of conditional choice probabilities are then incorporated into equation (3.6), which estimates parameters in the utility and the participation cost. 
In this section, I specify the functional form of the participation costs and households' preferences over consumption and investment choices, and then derive the equation to be estimated. Next, I discuss estimation of the nuisance parameters.

\subsection{Participation Cost}

I parameterize the participation cost $\rho$ as a function of a household's labor income as a monetary measure of the opportunity cost. I also allow the participation cost to be a function of age, education, and past participation choices as proxies for the experience and the ability to absorb and process financial knowledge and information. Specifically, I write participation cost as a linear combination of household's observed characteristics:

$$
\rho_{t}=\delta y_{t}^{l} x_{t}
$$

where $x_{t}=\left(1, e d u_{t}, a g e_{t}, a g e_{t}^{2}, d_{t-1}\right)$ and $y^{l}$ is labor income.

\subsection{Preferences}

Households derive utility from the consumption good, denoted by $u_{i t}^{c}=u\left(z_{i t}\right)$. I specify the utility of consumption in a quadratic form as

$$
u_{i t}^{c}=c_{t}-\xi_{t} c_{t}^{2}
$$

where $\xi_{t}$ can be a constant or a function of a household's demographic characteristics. Quadratic utility of consumption is one of the leading models in the financial industry because of its desirable mean-variance portfolio selection properties. In the current paper, its use is appealing because it renders the estimation problem as linear. A potential drawback is that the quadratic utility does not rule out the negative marginal utility of consumption. Therefore, once the estimation of the utility parameters is achieved, ruling out parameter values that allow marginal utility of consumption to be negative for all possible values of consumption data is important.

Additionally, I allow for a non-pecuniary utility cost of adjusting the share of wealth invested in risky assets. This cost is motivated by recent evidence on the reluctance of households to adjust financial portfolio frequently. For example, Brunnermeier and Nagel (2008) argue that inertia can drive households portfolio allocation. The utility cost of adjusting portfolio composition is denoted as $u_{i t}^{d}=u\left(d_{i t}, \alpha_{i t}, \alpha_{i t-1}\right)$ and 
specified as:

$$
u_{i t}^{d}=\gamma_{0} d_{i t}+\gamma_{1} \alpha_{i t} \alpha_{i t-1}
$$

where $\gamma_{0}$ is the choice specific utility shifter and $\gamma_{1}$ is the parameter of adjusting portfolio share invested in stocks between time $t-1$ and $t$.

Then the utility payoff for household $i$ is defined as $u_{j}\left(z_{i t}\right)=u_{i t}^{c}+u_{i t}^{d}$ for $j=0,1$ and depends on consumption, current and past investment choices, as well as other characteristics in state vector.

\subsection{The Moment Conditions}

I proceed to elaborate on equation (3.6). Although data on wealth and income are available, the PSID does not report total household consumption. To circumvent this problem, I compute the measure of a household's consumption from the budget constraint ${ }^{9}$ :

$$
\begin{aligned}
c_{i t} & =R_{i t}^{p} w_{i t-1}+y_{i t}-w_{i t}-d_{i t} \rho_{i t} \\
& =\hat{c}_{i t}^{p}-d_{i t} \rho_{i t},
\end{aligned}
$$

where $\hat{c}_{i t}^{p}$ is a function of a household's data and the return on portfolio. In addition, $\hat{c}_{i t}^{f}=R_{t}^{f} w_{i t-1}+y_{i t}-w_{i t}$ will also be used when the only return on household portfolio is the risk-free rate. Note that in the absence of stock market participation costs the above gives a measure of total consumption. Consumption is assumed to be additively separable from participation cost. The state vector $z_{i t}$, but not the contemporaneous decision to invest, affect the level of consumption and the utility derived from consumption in period $t$. However, the wealth in period $t$ becomes smaller by the amount of participation cost.

The key feature of the estimation of the participation cost is the intertemporal utility cost and benefit analysis for different participation strategies, where participation cost is connected to the amount of wealth households consider investing in stocks. On the one hand, participation cost reduces wealth today while potentially increasing household wealth in the next period, depending on the amount invested in stocks. On the other hand, households may choose not to invest in stocks today, and to keep all wealth (including the not-forgone participation cost) in risk-free assets. In the next period, however, the household can only receive a risk-free return on savings, including the not-foregone participation cost.

For illustration, consider two identical households $n$ and $i$ who act under two distinct participation strate-

\footnotetext{
${ }^{9}$ Browning and Leth-Petersen (2003) suggest and methodologically justify similar imputation of consumption expenditure from income and wealth data.
} 
gies (3.4) and (3.5), respectively. Recall that one of the strategies is to participate in period $t$ and quit stock markets in period $t+1$. The other strategy is to not participate in either period $t$ or $t+1$. Consider household $i$, whose observed choice is to participate in period $t$. I assume that the observed wealth is net participation cost: $w_{i t} \mid\left(d_{i t}=1\right)=R_{i t}^{p} w_{i t-1}+y_{i t}-c_{i t}-\rho_{i t}$. Period $t$ wealth of household $n$ will be greater than the wealth for household $i$ by the amount of the participation cost: $\left(w_{n t}+\rho_{n t}\right) \mid\left(d_{n t}=0\right)=R_{n t}^{p} w_{n t-1}+y_{n t}-c_{n t}$. The identical time $t$ state vector implies time $t$ consumption for both households is the same; therefore, utility of consumption for these households is identical in period $t$. Under these two strategies, however, period $t+1$ consumption may not be the same, because different wealth in period $t$ affects it. Under the first strategy, $c_{i t+1}=\left(\alpha_{i t}\left(R_{i t+1}^{s}-R_{t+1}^{f}\right)+R_{t+1}^{f}\right) w_{i t}+y_{i t+1}-w_{i t+1}$, whereas under the second strategy, $c_{n t+1}=R_{t+1}^{f}\left(w_{n t}+\rho_{n t}\right)+y_{n t+1}-w_{n t+1}$. We are unlikely to see two households with identical continuous state vectors in the data. Therefore, thinking about the same household that makes different participation choices in period $t$ after being affected by different shocks $\varepsilon$ can be intuitive. Looking at the transition of wealth from period $t$ to period $t+1$ under these participation strategies can illustrate their differences:

$$
\begin{array}{ll}
\text { Strategy } \quad\left(d_{t}=1, d_{t+1}=0, \ldots\right) & \text { Strategy } \quad\left(d_{t}=0, d_{t+1}=0, \ldots\right) \\
w_{t}=R_{t}^{p} w_{t-1}+y_{t}-c_{t}-\rho_{t} & w_{t}+\rho_{t}=R_{t}^{p} w_{t-1}+y_{t}-c_{t} \\
w_{t+1}=\left(\mathbf{R}_{\mathbf{t}+\mathbf{1}}^{\mathbf{s}}-\mathbf{R}_{\mathbf{t}+\mathbf{1}}^{\mathbf{f}}\right) \boldsymbol{\alpha}_{\mathbf{t}} \mathbf{w}_{\mathbf{t}}+R_{t+1}^{f} w_{t}+y_{t+1}-c_{t+1} & w_{t+1}=\mathbf{R}_{\mathbf{t}+\mathbf{1}}^{\mathbf{f}} \rho_{\mathbf{t}}+R_{t+1}^{f} w_{t}+y_{t+1}-c_{t+1}
\end{array}
$$

It follows that under two distinct strategies, a household chooses between giving up the amount $\rho_{t}$ in period $t$ and receiving an expected increase in wealth in the amount of $\left(R_{t+1}^{s}-R_{t+1}^{f}\right) \alpha_{t} w_{t}$ next period versus not participating in period $t$ and receiving $R_{t+1}^{f} \rho_{t}$ next period. Finite dependence is induced by assuming that once households $i$ and $n$, characterized by equivalent starting conditions at time $t$, choose not to invest in stock markets in period $t+1$, their choice of wealth should not differ by much. In period $t+2$, the state vector under both strategies becomes identical; therefore, the consumption and other quantities that determine value function in period $t+2$ become identical as well.

After taking differences in contemporaneous utilities, the utilities from consumption at time $t$ will cancel so that only the utility cost of adjusting one's portfolio will remain: $u_{1}\left(z_{i t}\right)-u_{0}\left(z_{i t}\right)=\gamma_{0} d_{i t}+\gamma_{1} \alpha_{i t} \alpha_{i t-1}$. Under both alternatives, time $t+1$ utility cost of adjusting one's portfolio equals zero, because no investment in stocks occurs in period $t+1$. The difference in utility payoffs from consumption at time $t+1$ is more involved. Denote consumption under participation strategy as $c_{t+1}^{1}$, and $c_{t+1}^{0}$ as consumption for 
non-participation strategy. Then the difference between utility payoffs is:

$$
\begin{array}{r}
c_{t+1}^{1}-c_{t+1}^{0}-\xi_{t}\left[\left(c_{t+1}^{1}\right)^{2}-\left(c_{t+1}^{0}\right)^{2}\right]= \\
\left(c_{t+1}^{1}-c_{t+1}^{0}\right)\left[1-\xi_{t}\left(c_{t+1}^{1}+c_{t+1}^{0}\right)\right]= \\
\left(\alpha_{t} \hat{w}_{t+1}-R_{t+1}^{f} \rho_{t}\right)\left[1-\xi_{t}\left(2 c_{t+1}^{f}+\alpha_{t} \hat{W}_{t+1}+R_{t+1}^{f} \rho_{t}\right)\right] .
\end{array}
$$

Substituting the differences in the utility payoffs into the optimality condition (3.6), I obtain the equation to be estimated:

$\ln \left(\frac{p_{1 i t}}{p_{0 i t}}\right)=\gamma_{0} d_{i t}+\gamma_{1} \alpha_{i t} \alpha_{i t-1}+\beta \sum_{k}^{K}\left[\left(\alpha_{i t} \hat{w}_{i t+1}^{k}-R_{t+1}^{f} \rho_{i t}\right)\left[1-\xi\left(2 c_{i t+1}^{f}+\alpha_{i t} \hat{w}_{i t+1}^{k}+R_{t+1}^{f} \rho_{i t}\right)\right]-\ln \frac{p_{0 k t+1}}{p_{00 i t+1}}\right] \mathcal{F}_{t+1}^{k}$,

where $\hat{w}_{i t+1}^{k}=w_{i t}\left(R_{i t+1}^{s k}-R_{i t+1}^{f}\right)$ is a function of the data.

Let $\Theta$ denote all unknown parameters in the model to be estimated. These parameters include the utility parameters $\gamma_{0}, \gamma_{1}$, and $\xi$ and the parameters of the participation cost $\delta$. I fix the value of time discount factor $\beta$ and estimate the remaining parameters conditioning on $\beta$. I rearrange and combine terms represented by observables to get the equation:

$$
m_{i t}(\Theta)=Y_{i t}-X_{i t} \Theta
$$

where

$$
\begin{aligned}
Y_{i t} & =\ln \left(\frac{p_{1 i t}}{p_{0 i t}}\right)-\beta \sum_{k}^{K}\left[\alpha_{i t} \hat{w}_{i t+1}^{k}-\ln \frac{p_{0 k t+1}}{p_{00 i t+1}}\right] \mathcal{F}_{t+1}^{k} \\
X_{i t} & =\left(\begin{array}{lllll}
1, & \alpha_{i t} \alpha_{i t-1}, & \beta R_{t}^{f} y_{i t}^{l} x_{i t}, & \left.\beta \sum_{k}^{K} \alpha_{t} \hat{w}_{t+1}^{k}\left(2 c_{t+1}^{f}+\alpha_{t} \hat{w}_{t+1}^{k}\right) \mathcal{F}_{t+1}^{k}, \quad 2 \beta R_{t}^{f} c_{t+1}^{f} y_{i t}^{l} x_{i t}, \quad \beta R_{t}^{f 2} \sum_{l=1}^{L} x_{l i t}^{2}, \quad 2 \beta R_{t}^{f 2} \sum_{l=1}^{L-1} \sum_{q=l+1}^{L} x_{l i t} x_{q i t}\right) .
\end{array}\right.
\end{aligned}
$$

where $L$ is the dimension of $x_{i t} . \Theta=\left(\Theta_{1}, \Theta_{2}\right)$, where $\Theta_{1}=\left(\gamma_{0}, \gamma_{1}, \delta, \xi\right)$ has dimension $2+L+H$, and $\Theta_{2}=(\xi \delta$, $\left.\xi \delta^{2}, \xi\left(\delta_{1} \delta_{2}, \ldots, \delta_{L-1} \delta_{L}\right)\right)$ has dimension $2 H L+H L(L-1) / 2$, where $\delta$ is a vector of parameters $\left(\delta_{1}, \ldots, \delta_{L}\right)$ with the same dimension as $x_{i t}$ and $H$ is the dimension of $\xi$. My primary interest is only in $\Theta_{1}$. In the estimation, I do not impose any restrictions on $\Theta_{2}$ and estimate the unrestricted equation (4.1) that is linear in parameters.

If I were to observe or estimate the conditional choice probabilities and the transition probabilities, I 
could estimate the unknown structural parameters of interest from a conditional moment condition

$$
E\left[m\left(X_{i t}, Y_{i t}, \Theta_{o}\right) \mid z_{i t}\right]=0,
$$

where subscript $o$ denotes the true value of the parameters. The minimum distance estimator is a natural estimator choice in this and similar frameworks.

\subsection{Individual Effects and Aggregate Shocks}

Microeconometric literature has proposed different methods for incorporating unobserved heterogeneity in dynamic discrete choice models. Altug and Miller (1998) estimate fixed effects from an auxiliary regression related to the main model. More recent studies by Aguirregaberia and Mira (2007), Kasahara and Shimotsu (2009), and Arcidiacono and Miller (2011) propose alternative ways through finite mixture distributions. The approach of Kasahara and Shimotsu is restrictive for my estimation. For identification of unobserved heterogeneity, their approach requires the time dimension of a panel that is beyond the one available in the data at hand. The identification requirements in Arcidiacono and Miller are similar to those in the study of Kasahara and Shimotsu. I adopt the approach of Altug and Miller and use the earnings equation to estimate individual unobserved effects.

The same earnings equation allows me to estimate time effects as well. In my framework, current wealth accumulation is affected by aggregate shocks through current wages and rates of return. Aggregate shocks

on rates of return are captured by the risk-free rate, $R_{t}^{f}$. Aggregate shocks on wages are not directly observed, but can be estimated.

I assume both time effects and individual effects impact a household's earnings are affected by both time effects and individual effects; hence I can estimate these effects by modeling the household's earnings process. I consider a dynamic earnings equation of the form:

$$
\hat{y}_{i t}=\phi \hat{y}_{i t-1}+x_{i t}^{\prime} \kappa+\omega_{t}+v_{i}+e_{i t}
$$

where $\hat{y}_{i t}$ is the log-transformation of a household's labor income and $x_{i t}^{\prime}$ is an $L$-dimensional vector of family characteristics for household $i$ at time $t, \omega_{t}$ is the unobserved time-specific effect, and $v_{i}$ is the unobserved individual-specific effect. I follow Arellano and Honore (2001) in assuming the predeterminedness condition of $\hat{y}_{i t-1}$ and (possibly) $x_{i t}$, precisely $E\left(e_{i t} \mid \hat{y}_{i}^{t-1}, x_{i}^{t}\right)=0$ and $E\left(v_{i}\right)=0$. Subject to a rank condition, $(1+L+$ 
$T-1$ ) parameters of the model (4.3) are identified with $T \geqslant 3$. With $T=3 \phi, \kappa^{\prime} \mathrm{s}, \omega_{2}$, and $\omega_{3}$ are just identified from the $3+L$ orthogonality conditions:

$$
\begin{aligned}
& E\left[\left(\begin{array}{c}
1 \\
x_{i t}^{\prime} \\
\hat{y}_{i t-2}
\end{array}\right)\left(\Delta \hat{y}_{i t}-\phi \Delta \hat{y}_{i t-1}-\Delta x_{i t}^{\prime} \kappa-\Delta \omega_{t}\right)\right]=0 \\
& E\left(\hat{y}_{i t}-\phi \hat{y}_{i t-1}-x_{i t}^{\prime} \kappa-\omega_{t}\right) \quad=0,
\end{aligned}
$$

Estimation of the fixed effects, however, requires a larger $T$. The extended data set covers $T=14$ time periods of observations. The vector of family characteristics $x_{i t}^{\prime}$ contains three variables - family size, education multiplied by age and age squared. It makes 17 parameters to estimate. The overidentified system of equations (4.3) contains four moment conditions for each of $T-2$ time periods, producing up to 48 orthogonality conditions for each household. The four moment conditions include the unconditional moment condition in levels and the moment conditions in first differences with a constant, income at time $t-2$, and age squared at time $t$ as instruments. I estimate the system of equations (4.4) with the GMM procedure.

Table 4 reports the estimates of the earning equation (4.3). The estimates on family size, education, and age are consistent with the general expectations. Household income increases with family size. It responds positively to the level of education and decreases with the household growing older. The $A R(1)$ coefficient on past earnings is estimated at 0.85 and is statistically significant. Most estimates on $\Delta \omega_{t}$ are also statistically significant. With the parameter estimates of model (4.3), individual fixed effects are trivially estimated.

\subsection{Conditional Choice Probabilities}

Following the methodology developed in Hotz and Miller (1993) and Altug and Miller (1998), I compute the conditional choice probabilities nonparametrically using a kernel estimator. The conditional choice probability $p_{j}\left(z_{l k i t}\right), j, l=0,1$ and $k=0, \ldots, K$, is denoted as a probability of choosing the participation alternative $j$ by household $i$ in period $t$ given that the alternative $l$ was chosen in period $t-1$ and conditioned on realization of the state $z_{l k i t}$. Table 5 reports the summary of nonparametric estimates of conditional choice probabilities. The table also reports the number of observations used to compute the probability associated with each relevant history $z_{l k i t}$ as well as sample standard deviations. The estimated conditional choice probabilities are limited to those relevant to the histories employed to derive equation (3.6).

Line one of Table 5 reports the participation rate $p_{1 i t}$. Line 2 reports the probability of not participating 
Table 4: Earnings equation ${ }^{1}$

\begin{tabular}{lcc}
\hline \hline & & \\
Parameter & Estimate & Std.Err. \\
& & \\
\hline & & \\
$\kappa^{\prime} s:$ & 0.856 & 0.038 \\
family size & 0.202 & 0.037 \\
edu*age & 0.577 & 0.063 \\
age $e^{2}$ & -0.863 & 0.088 \\
& & \\
$\omega_{1983}$ & -0.720 & 0.357 \\
$\Delta \omega_{1985}$ & 0.078 & 0.015 \\
$\Delta \omega_{1987}$ & -0.063 & 0.014 \\
$\Delta \omega_{1989}$ & -0.025 & 0.013 \\
$\Delta \omega_{1991}$ & -0.088 & 0.013 \\
$\Delta \omega_{1993}$ & 0.012 & 0.013 \\
$\Delta \omega_{1995}$ & -0.108 & 0.016 \\
$\Delta \omega_{1997}$ & 0.031 & 0.017 \\
$\Delta \omega_{1999}$ & 0.084 & 0.018 \\
$\Delta \omega_{2001}$ & -0.025 & 0.015 \\
$\Delta \omega_{2003}$ & -0.071 & 0.015 \\
$\Delta \omega_{2005}$ & 0.057 & 0.017 \\
$\Delta \omega_{2007}$ & -0.008 & 0.019 \\
& & \\
\hline & & \\
\hline test & 10.5 & \\
$p$ value & 0.99 & \\
\hline \hline & & \\
\hline
\end{tabular}

${ }^{1}$ Number of time periods $\mathrm{T}=14$, number of households in the sample 7,744. Instruments include a constant, age of head of household squared at time $t$, and labor income at time $t-2$.

Table 5: Sample averages of nonparametric estimates of conditional choice probabilities

Num.obs. Sample mean Sample std.dev.

\begin{tabular}{llccc} 
& & Num.obs. & Sample mean & Sample std.dev. \\
\hline \hline & & & & \\
1. & $p_{1 i t}$ & 10,639 & 0.256 & 0.300 \\
2. & $p_{0}\left(z_{0 i t}\right)$ & 9,412 & 0.889 & 0.089 \\
3. & $p_{0}\left(z_{\text {Hit }}\right)$ & 10,590 & 0.030 & 0.108 \\
4. & $p_{0}\left(z_{\text {Mit }}\right)$ & 10,588 & 0.016 & 0.084 \\
5. & $p_{0}\left(z_{\text {Lit }}\right)$ & 10,608 & 0.138 & 0.248 \\
\hline \hline
\end{tabular}


in the stock markets in period $t$ conditional on not participating in period $t-1$. Lines three, four, and five report the probability of not participating in stock markets in period $t$ conditional on participation in the previous time period and receiving high, moderate, or low return on the investment in stocks. The average estimated participation rate is 0.25 . The results also suggest the probability of participation decreases if a previous period has an incidence of nonparticipation to 0.11 .

\section{Empirical Findings}

Table 6 contains the estimation results for the utility parameters and parameters of the participation cost. Columns (1)-(3) report estimates for the model with the simple quadratic utility of consumption, columns (4)-(6) report estimates for the model with age-augmented quadratic utility of consumption. The table reports the total number of parameters estimated by each model specification, but only includes $\gamma_{0}, \gamma_{1}, \delta^{\prime}$, and $\xi^{\prime} \cdot 10$

\section{Participation cost}

Columns (1) and (4) of Table 6 show the participation cost is estimated on average to be about $4 \%$ to $6 \%$ of labor income. The participation cost measured as a share of income is not constant over the life cycle and admits the curvature of the labor income profile. Results in columns (2)-(3) and (5)-(6) provide evidence that, even holding labor income fixed, age, education, and previous participation affect participation costs. Table 6 shows the participation cost is decreasing in education. It is roughly decreasing with age. When I introduce the curvature in age in the participation cost, it becomes increasing and concave with age, with the turning point around ages 35-40. Finally, the participation cost is smaller for households that participated previously in stock markets.

The estimation results for the participation cost seem to be intuitive and agree with previous findings. First, Gomes and Michaelides (2003) rationalize limited participation by the existence of the participation cost. Second, empirical findings of Bertaut and Starr-McCluer (2002), Guiso and Japelli (2002), and Banks and Tanner (2002) show individual characteristics such as age and education can explain participation in stock markets. Finally, past participation also affects future participation. Alessie, Hochguertel, and van Soest, (2002, 2004), and Munoz (2006) empirically confirm this dynamic dependence. The estimation results in the current study relate to these findings and show the participation cost is significantly different from zero and varies with household characteristics.

\footnotetext{
${ }^{10}$ The full set of parameter estimates is available from the author.
} 
Table 6: Participation cost and utility parameters.

\begin{tabular}{|c|c|c|c|c|c|c|}
\hline Parameters & $(1)$ & $(2)$ & (3) & (4) & $(5)$ & $(6)$ \\
\hline \multicolumn{7}{|c|}{ Utility parameters $\left(c_{t}-\xi_{t} c_{t}^{2}\right)+\gamma_{0} d_{t}+\gamma_{1} \alpha_{t} \alpha_{t-1}$} \\
\hline & \multicolumn{3}{|c|}{$\xi_{t}=\xi_{1}$} & \multicolumn{3}{|c|}{$\xi_{t}=\xi_{1}+\xi_{2} a g e_{t}$} \\
\hline$\gamma_{0}$ & $\begin{array}{c}24.414 \\
(3.829)\end{array}$ & $\begin{array}{c}34.174 \\
(4.653)\end{array}$ & $\begin{array}{c}33.183 \\
(5.403)\end{array}$ & $\begin{array}{c}20.588 \\
(3.852)\end{array}$ & $\begin{array}{c}30.590 \\
(4.896)\end{array}$ & $\begin{array}{r}25.337 \\
(7.122)\end{array}$ \\
\hline$\gamma_{1}$ & $\begin{array}{c}11.535 \\
(7.739)\end{array}$ & $\begin{array}{c}-5.906 \\
(8.998)\end{array}$ & $\begin{array}{c}-5.344 \\
(9.680)\end{array}$ & $\frac{11.112}{(7.898)}$ & $\begin{array}{c}-0.501 \\
(7.082)\end{array}$ & $\begin{array}{l}2.110 \\
(8.336)\end{array}$ \\
\hline$\xi_{1}$ & $\begin{array}{c}0.00051 \\
(0.00015)\end{array}$ & $\begin{array}{c}0.00046 \\
(0.00015)\end{array}$ & $\begin{array}{c}0.00046 \\
(0.00015)\end{array}$ & $\begin{array}{c}-0.00028 \\
(0.00071)\end{array}$ & $\begin{array}{c}-0.00036 \\
(0.00084)\end{array}$ & $\begin{array}{c}-0.00009 \\
(0.00083)\end{array}$ \\
\hline$\xi_{2}$ & & & & $\begin{array}{c}0.000016 \\
(0.000013)\end{array}$ & $\begin{array}{c}0.000019 \\
(0.000016)\end{array}$ & $\begin{array}{c}0.000015 \\
(0.000016)\end{array}$ \\
\hline \multicolumn{7}{|c|}{ Participation cost $\rho_{t}=y_{t}\left(\delta_{1}+\delta_{2} e d u+\delta_{3} a g e_{t}+\delta_{4} a g e_{t}^{2}+\delta_{5} d_{t-1}\right)$} \\
\hline$\delta_{1}$ & $\begin{array}{l}0.061 \\
(0.019)\end{array}$ & $\begin{array}{l}0.377 \\
(0.093)\end{array}$ & $\begin{array}{l}0.043 \\
(0.221)\end{array}$ & $\begin{array}{l}0.042 \\
(0.019)\end{array}$ & $\begin{array}{l}0.352 \\
(0.108)\end{array}$ & $\begin{array}{l}0.0344 \\
(0.3124)\end{array}$ \\
\hline$\delta_{2}$ & & $\begin{array}{c}-0.0163 \\
(0.0049)\end{array}$ & $\begin{array}{c}-0.0180 \\
(0.0050)\end{array}$ & & $\begin{array}{c}-0.0158 \\
(0.0058)\end{array}$ & $\begin{array}{c}-0.0157 \\
(0.0072)\end{array}$ \\
\hline$\delta_{3}$ & & $\begin{array}{c}-0.0007 \\
(0.0009)\end{array}$ & $\begin{array}{c}0.0170 \\
(0.0096)\end{array}$ & & $\begin{array}{c}-0.0005 \\
(0.0011)\end{array}$ & $\begin{array}{c}0.0146 \\
(0.0130)\end{array}$ \\
\hline$\delta_{4}$ & & & $\begin{array}{c}-0.00021 \\
(0.00011)\end{array}$ & & & $\begin{array}{c}-0.00019 \\
(0.00015)\end{array}$ \\
\hline$\delta_{5}$ & & $\begin{array}{c}-0.0246 \\
(0.0137)\end{array}$ & $\begin{array}{c}-0.0284 \\
(0.0139)\end{array}$ & & $\begin{array}{c}-0.0322 \\
(0.0154)\end{array}$ & $\begin{array}{c}-0.0363 \\
(0.0194)\end{array}$ \\
\hline Number of parameters & 6 & 20 & 26 & 9 & 34 & 46 \\
\hline$J$-test & 98 & 112 & 125 & 107 & 134 & 138 \\
\hline$p$-value & $5 e-7$ & $4 e-4$ & $7 e-4$ & $5 e-7$ & 0.0051 & 0.087 \\
\hline
\end{tabular}

Standard errors in parenthesis. Standard errors are estimated using a bootstrap method with 200 replications. 

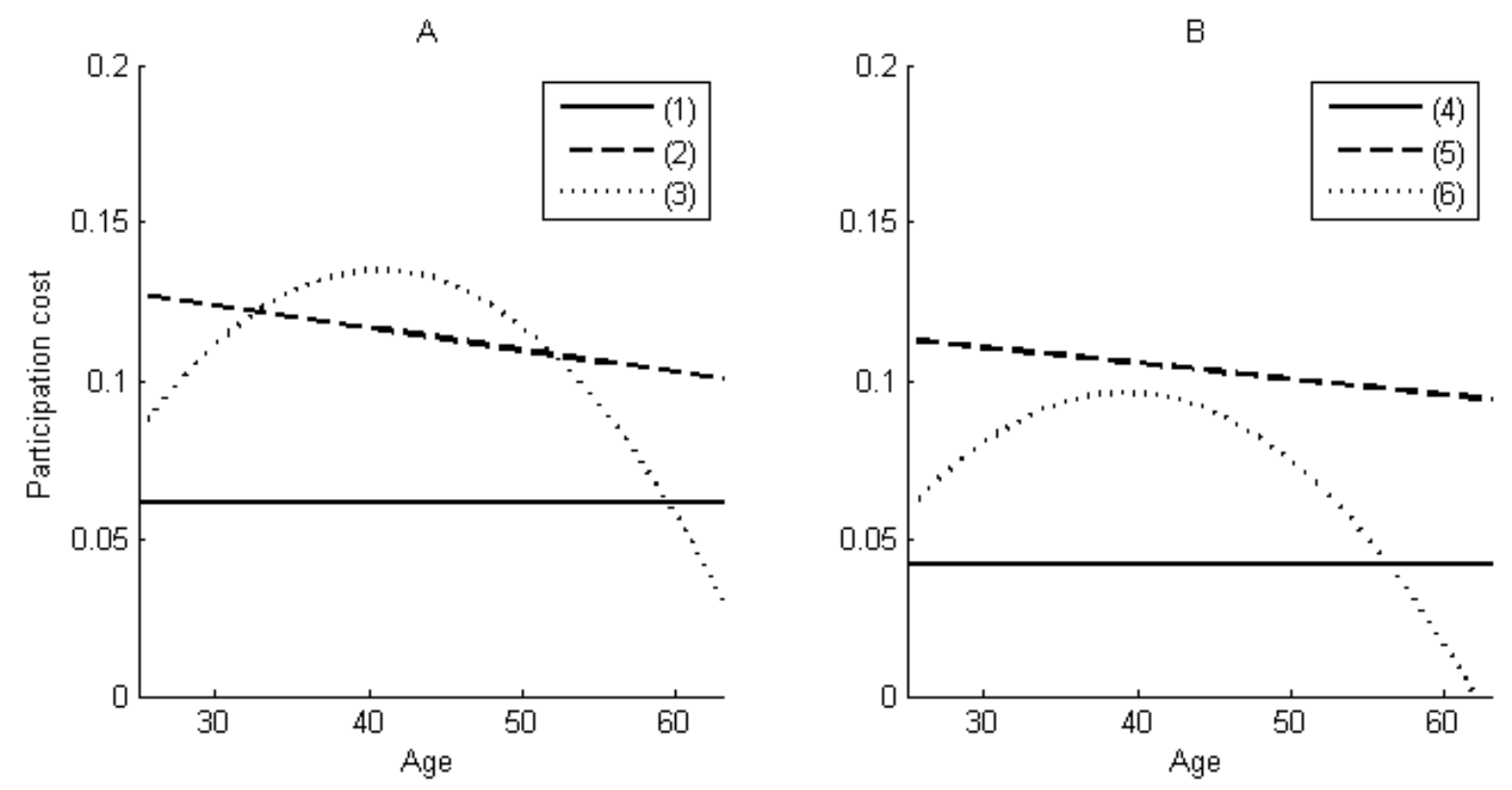

Figure 1: Age profile of the participation cost as a share of labor income.

Education and past participation are fixed at the sample average level.

Figure 1 illustrates how participation cost (as a share of labor income) changes over age, with other demographic characteristics fixed at their sample average levels. Panel A presents the age profile of the participation cost computed using parameter estimates from Table 6, columns (1)-(3), while panel B presents the same for columns (4)-(6). Participation cost can be as great as $10 \%$ of labor income, but also can decrease to negligible values. On average, participation cost in columns (1)-(3) is greater than in columns (4)-(6) by about 2 percentage points of labor income. The effect of age on both the participation cost and the utility can explain these differences. The specification in columns (4)-(6) is different from the one in columns (1)-(3) only through the age-dependent parameter $\xi_{t}$ in the utility of consumption. Once the age is controlled for in the curvature of the utility of consumption, the effect of age on participation cost decreases.

Overall, the estimation results provide additional support for the empirical findings of Paiella (2007) and Attanasio and Paiella (2011). The estimated participation cost is on average much greater than the lower bound estimates in these studies. Also, the estimated per period participation costs support the existence of fixed entry costs used in the theoretical papers of Gomes and Michaelides (2003), Haliassos and Michaelides (2003) and related studies. Column (6) suggests per-period participation costs are substantially smaller (by $3.6 \%$ ) for investors with previous stock market participation experience. This finding implies first timeparticipants face larger participation costs that potentially include a fixed entry cost.

On the one hand, if a consumer faces only fixed entry costs while making a decision to invest in stocks, 
then once he decides in favor of investing, quitting the stock market and returning later is not costly for him. In this case, he has already incurred the cost and the information he obtained when entering the stock market the first time, never depreciates. On the other hand, participation cost can measure the ongoing effort to gather the information related to investment in stocks, and the knowledge an investor gained in previous periods may still be relevant in the current period. However, the longer ago an investor obtained the knowledge, the less applicable and relevant it may be to the current state of the stock market. The per-period participation cost can, therefore, capture the effect of the diminishing relevance of previous knowledge and experience.

Because of the limitations along the time dimension of the panel data, I allow for one lag of the participation dummy to affect the current participation cost. In general, one can test the relevant importance of the entry cost and per-period cost with the flexible form of the participation cost if we allow more lags in the participation. This allowance is possible at the expense of the reduction of the time dimension in the panel used in estimation. I defer the extension of the model along this line of research for future work.

\section{Utility parameters}

Utility parameters include the curvature parameters in the utility of consumption, the utility shifter for stock market participants, and parameters of the adjustment of portfolio allocation. The estimates of the $\xi_{t}$ are significant in all model specifications and indicate the utility of consumption is concave. The average value of $\xi_{t}=\xi_{1}+\xi_{2}$ age $e_{t}$ is similar to the estimates of $\xi_{t}$ in columns (1)-(3). Even with the negative $\xi_{1}$ in columns (5) and (6), $\xi_{t}$ never takes negative values. Additionally, the estimates imply a positive marginal utility of consumption for all consumption values in the data.

All model specifications in Table 6 suggest the existence of a positive utility shifter for the households that participate in stock markets. The parameter of the portfolio adjustment cost is not significantly different from zero. The positive estimate of $\gamma_{1}$ would indicate a complimentarity effect of past portfolio allocation on current portfolio allocation, and would also provide evidence on the effect of inertia, found by Brunnermeier and Nagel (2008). However, the current estimation outcome does not allow a revelation of such effects in a precise manner.

The $J$ tests associated with the model specifications reported in Table 6 indicate the rejection of overidentifying restrictions implied by the choice of instruments for specifications (1) through (5). However, the model specification (6) cannot be rejected at the 5\% significance level. I use the parameter estimates from this specification to evaluate how the model fits to the data. 


\section{Model Fit}

The simulation exercise in this section is aimed to show how the estimated model fits the stock market participation pattern observed in the data. I solve the model via backward induction using the estimated parameters reported in column (6) of Table 6. As the estimation uses biannual data, I also solve the model recursively on a biannual basis. To align with the estimation set-up that considers households prior to retirement (i.e. before age 65), I simulate households up to the retirement stage.

To solve for the optimal share of wealth invested in risky assets and total wealth, I first define a fine grid on state variables that include past share of wealth invested in risky stocks and past wealth with earned rate of return, as well as income. I achieve the interpolation off the grid with the second order polynomial regression of the value function at each point of the grid on the corresponding state space vector. ${ }^{11}$ This regression provides an accurate approximation to the value functions off the grid with $R^{2}$ in the range of 0.98-0.99.

Once I obtain the solution, I simulate the model, producing 5,000 replications. ${ }^{12}$ I choose no participation in stock markets as a starting condition for all simulated individuals. Conditional on the state variables, I compute the conditional choice value function for each combination of the choice variables from the grid, using the interpolation coefficients obtained at the solution as well as the draws of extreme value random variables. Then I select the maximal conditional choice value function and find the optimal choice of participation decision, portfolio choice, and wealth associated with the maximal value function. If a simulated consumer finds participating in stock markets is optimal, he receives the rate of return of stock holdings, drawn randomly as low, moderate, or high return with corresponding probabilities used in estimation as transition probabilities.

Figure 2 compares (1) the average age-specific participation rate computed from the data, (2) participation rate, predicted by the probit model, which I estimated earlier in the section on the data description, and (3) participation rate, predicted by the structural model. The participation rate generated by the probit model is reported for comparison. The probit model employs a somewhat richer set of covariates, including time dummies and cohort effects, in a simpler and flexible model structure that, however, does not allow for explicit modeling of participation costs. As shown in Figure 2, the structural model with its more complex structure and explicit accounting for participation costs successfully predicts the stock market participation

\footnotetext{
${ }^{11}$ A higher order polynomial regression was also tried; however, it produces less accurate predictions.

${ }^{12} \mathrm{~A}$ greater number of simulations makes little difference.
} 


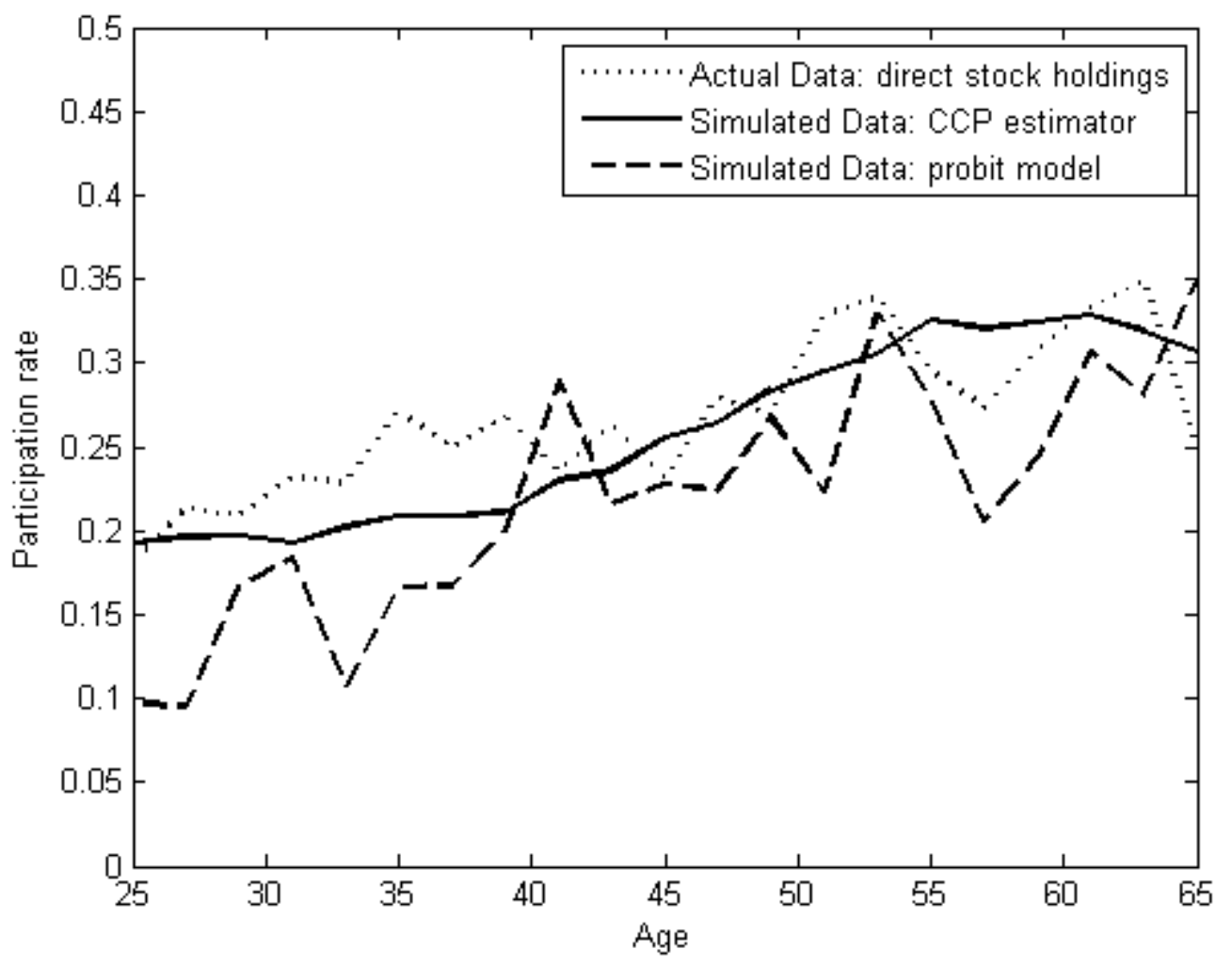

Figure 2: Participation rate: Data vs Simulation 
rate observed in the data. The model also produces the increasing pattern of stock market participation over the life cycle.

\section{Conclusion}

In this paper, I attempt to rationalize the limited stock market participation at the micro-data level. I develop and estimate a dynamic structural model of individual stock market participation and portfolio choice, where decisions regarding stock market participation are influenced by participation costs. The practical significance of the participation costs is considered as being a channel through which financial education programs can affect consumers investment decisions. Financial education and counseling alleviates the burden on consumers time and the effort necessary for making financial decisions and reduces the objective cost of stock market participation. The estimation results support the existence of a significant cost of stock market participation that, on average, is about $5 \%$ of labor income. These results augment the findings on the lower bound of the stock market participation cost currently available in the empirical literature, but also are in accordance with the fixed entry costs used in the theoretical literature.

The estimated model not only supports empirically the strand of the theoretical and empirical literature that utilizes participation costs to explain limited stock market participation, but also facilitates simulated paths for the decision to participate in stock markets that successfully line up with patterns observable in the data. While the theoretical models of stock market participation with participation costs are able to generate lower participation rates, the predicted levels of participation in stock markets are still substantially greater than those observed in the data. The striking accuracy of the estimated structural model is likely due to its richer stochastic environment and more sophisticated accounting for individual heterogeneity.

Overall, this paper is the first analysis of the stock market participation and portfolio composition that allows for heterogeneity in the participation cost and estimates the magnitude of it using micro data. The empirical evidence suggest the participation costs decrease with stock market participation experience and as consumers become older, and are less for more educated investors. In general, the results contribute to the broad strand of the literature on life-cycle consumption and savings decisions, as well as on the idiosyncratic response to consumer financial protection policy initiatives. 


\section{References}

[1] Aguirregabiria, Victor, and Pedro Mira (2007). "Sequential Estimation of Dynamic Discrete Games," Econometrica, $75,1-54$.

[2] Alan, Sule. (2006) "Entry Costs and Stock Market Participation Over the Life Cycle", Review of Economic Dynamics, 9(4).

[3] Alessie Rob, Stefan Hochguertel, and Arthur van Soest (2002), "Household Portfolios in the Netherlands", in Household Portfolios (Luigi Guiso, Michael Haliassos, and Tullio Jappelli, eds.). Cambridge, Massachusetts: MIT Press.

[4] Alessie Rob, Stefan Hochguertel, and Arthur van Soest (2004), "Ownership of Stocks and Mutual Funds: A Panel Data Analysis," The Review of Economics and Statistics, vol. 86(3), 783-796.

[5] Alessie Rob, Annamaria Lusardi and Maarten van Rooij, (2007). "Financial Literacy and Stock Market Participation," NBER Working Paper.

[6] Altug, Sumru and Robert A. Miller, (1990). "Household Choices in Equilibrium," Econometrica, 58, 543570 .

[7] Altug, Sumru and Robert A. Miller, (1998). "Effect of Work Experience of Female Wages and Labour Supply," The Review of Economic Studies, 65, 4585.

[8] Andersen, Steffen and Kasper Meisner Nielsen (2011), "Participation Constraints in the Stock Market: Evidence from Unexpected Inheritance Due to Sudden Death", The Review of Financial Studies, 24(5), $1667-1697$.

[9] Arcidiacono, Peter and Robert A. Miller (2011), "CCP Estimation of Dynamic Discrete Choice Models with Unobserved Heterogeneity", Econometrica, forthcoming.

[10] Arellano, Manuel and Bo Honore (2001), "Panel data models: some recent developments," in: J.J. Heckman and E.E. Leamer (ed.), Handbook of Econometrics, edition 1, volume 5, chapter 53, 32293296.

[11] Attanasio Orazio P. and Monica Paiella, (2011), "Intertemporal Consumption Choices, Transaction Costs and Limited Participation in Financial Markets: Reconciling Data and Theory", Journal of Applied Econometrics, 26(2), 322343.

[12] Banks James and Sarah Tanner (2002), "Household Portfolios in the United Kingdom", in Household Portfolios (Luigi Guiso, Michael Haliassos, and Tullio Jappelli, eds.). Cambridge, Massachusetts: MIT Press.

[13] Bertaut Carol C. and Martha Starr-McCluer (2002), "Household Portfolios in the United States", in Household Portfolios (Luigi Guiso, Michael Haliassos, and Tullio Jappelli, eds.). Cambridge, Massachusetts: MIT Press.

[14] Browning, Martin, and Sren Leth-Petersen (2003), "Imputing Consumption from Income and Wealth Information”, The Economic Journal, 113(488), 282-301.

[15] Brunnermeier Markus K. and Stefan Nagel (2008), "Do Wealth Fluctuations Generate Time-varying Risk Aversion? Micro-Evidence on Individuals' Asset Allocation”, American Economic Review, 98(3), 713-736. 
[16] Calvet, Laurent, John Campbell, and Paolo Sodini (2007), "Down or Out: Assessing the Welfare Costs of Household Investment Mistakes", Journal of Political Economy, 115, 707-747.

[17] Cocco, Joao F., Francisco J. Gomes and Pascal J. Maenhout, (2005) "Consumption and portfolio choice over the life-cycle", The Review of Financial Studies, 18, 491-533.

[18] Duflo Esther and Emmanuel Saez, (2003). "The Role Of Information And Social Interactions In Retirement Plan Decisions: Evidence From A Randomized Experiment," The Quarterly Journal of Economics, vol. 118(3), 815-842

[19] Gomes Francisco J. and Alexander Michaelides, (2003) "Portfolio Choice with Internal Habit Formation: a Life-cycle Model with Uninsurable Labor Income Risk", Review of Economic Dynamics, 6, 729-766.

[20] Gomes Francisco J. and Alexander Michaelides, (2005) "Optimal Life-Cycle Asset Allocation: Understanding the Empirical Evidence", The Journal of Finance, 60(2), 869-904.

[21] Grinblatt Mark , Juhani Linnainmaa, and Matti Keloharju (2010), "IQ and Stock Market Participation”, Working paper.

[22] Guiso Luigi and Tullio Jappelli (2002), "Household Portfolios in Italy", in Household Portfolios (Luigi Guiso, Michael Haliassos, and Tullio Jappelli, eds.). Cambridge, Massachusetts: MIT Press.

[23] Guiso Luigi and Tullio Jappelli (2005), “Awareness and Stock Market Participation”, Review of Finance, 9(4), 537-567.

[24] Haliassos, Michael, and Carol C. Bertaut (1995) "Why Do So Few Hold Stocks?", The Economic Journal, 105, 11101129.

[25] Haliassos, Michael and Alexander Michaelides, (2003), "Portfolio Choice and Liquidity Constraints". International Economic Review, 44(1), 143-177.

[26] Heaton, John and Deborah Lucas, (2000). "Portfolio Choice and Asset Prices: The Importance of Entrepreneurial Risk," Journal of Finance, 55(3), 1163-1198.

[27] Heckman, James J., (1979), "Sample selection bias as a specification error", Econometrica, 47, 153161.

[28] Hong, Harrison, Jeffrey D. Kubik, and Jeremy C. Stein, (2004), "Social interaction and stock market participation", Journal of Finance 59, 137-163.

[29] Hotz, V. Joseph, Kydland, Finn E. and Sedlacek, Guilherme L, (1988). "Intertemporal Preferences and Labor Supply," Econometrica, 56(2), 335-60.

[30] Hotz, Joseph V. and Robert A. Miller (1993) "Conditional choice probabilities and the estimation of dynamic models". Review of Economic Studies, 60(3), 497530.

[31] Kasahara Hiroyuki and Katsumi Shimotsu (2009) "Nonparametric Identification of Finite Mixture Models of Dynamic Discrete Choices,” Econometrica, 77(1), 135-175.

[32] Munoz Sonia (2006) "Habit Formation and Persistence in Individual Asset Portfolio Holdings: The Case of Italy”, IMF Working Paper No. 06/29.

[33] Paiella Monica (2007), "The Forgone Gains of Incomplete Portfolios", Review of Financial Studies, 20, 1623-1646. 
[34] Shapiro, Matthew D. (1984), "The Permanent Income Hypothesis and the Real Interest Rate". Economics Letters, 14, 93-100.

[35] Vissing-Jorgensen, Annette.(2002) "Towards an Explanation of Household Portfolio Choice Heterogeneity: Nonfinancial Income and Participation Cost Structures", NBER Working Paper. 